\title{
Optimising Ventilator Use during the COVID-19 Pandemic
}

\author{
Sadaf Sheikh ${ }^{1}$ and Muhammad Akbar Baig ${ }^{2}$ \\ ${ }^{1}$ Sultan Qaboos University Hospital, Muscat, Oman \\ ${ }^{2}$ The Aga Khan University Hospital, Karachi, Pakistan
}

\begin{abstract}
Hypoxemia is the most common cause for hospitalization in COVID-19 patients. Acute hypoxemic respiratory failure or acute respiratory distress syndrome (ARDS) is the most common complication in COVID-19 patients. Close monitoring of respiratory decompensation is essential. Supplemental oxygen, high flow nasal canula, non-invasive ventilation and endotracheal intubation are the most commonly suggested methods to improve oxygenation. Early intubation with preoxygenation, modified rapid sequence intubation and intubation using a video laryngoscope has been advised as a strategy including lung protective ventilation, prone position ventilation, adequate sedation and extracorporeal membrane oxygenation. Strict personal precautions and challenges related to airway management has been currently studied. The authors summarize here the issues of mechanical ventilation and some strategies to resolve them.
\end{abstract}

Key Words: Mechanical ventilation, COVID-19, Hypoxemia

How to cite this article: Sheikh S, Baig MA. Optimising Ventilator Use during the COVID-19 Pandemic. J Coll Physicians Surg Pak 2020; 30(JCPSPCR):CR46-CR47 https://doi.org/10.29271/jcpsp.2020.JCPSPCR.CR46.

Clinical spectrum of COVID-19 patients revolves around asymptomatic carriers, upper respiratory tract infections, pneumonia, heart failure, myocarditis, coagulopathy and severe forms of ARDS. Organ dysfunction including injury to heart, liver and kidney is common in the critically ill patients. ${ }^{2}$ Patients presented with dyspnea, tachypnea, desaturation with oxygen saturation less than $90 \%$, partial pressure $\left(\mathrm{PaO}_{2}\right)$ to fraction of inspired oxygen $\left(\mathrm{FIO}_{2}\right.$ ) less than $300 \mathrm{mmHg}$ and lung infiltration more than $50 \%$ within 48 hours. ${ }^{2}$ It was observed that relatively asymptomatic hypoxemia ('silent hypoxemia') may be responsible for the rapid deterioration and gives a false sense of wellbeing when oxygen debt is been asymptomatically increasing in COVID patients.

Endotracheal intubation was performed in $2.3 \%$ of 1099 COVID-19 patients in China $^{1-2}$ during the outbreak. Patients with cardiopulmonary arrest and acute respiratory failure due to COVID-19 were intubated empirically in particular with those patients showing no improvement with non-invasive ventilation, persistent respiratory distress and poor oxygenation $\left(\mathrm{PaO}_{2}\right.$ to $\mathrm{FIO}_{2}$ ratio less than $150 \mathrm{mmHg}$ ) after 2-hours of high-flow oxygen therapy or noninvasive ventilation. ${ }^{3}$ There is no supporting evidence towards early intubation could save more lives however many authorities including American Heart Association, are suggesting it. ${ }^{3}$

Correspondence to: Dr. Sadaf Sheikh, Department of Emergency Medicine, Sultan Qaboos University Hospital, Muscat, Oman

E-mail: sheikh.sadaf@gmail.com

Received: April 06, 2020; Revised: May 17, 2020;

Accepted: May 23, 2020

DOI: https://doi.org/10.29271/jcpsp.2020.JCPSPCR.CR46
Studies showed that delayed decision for intubation was related to adverse outcomes. ${ }^{3}$ It should be used as a 'salvage therapy' when oxygenation was declining. The most recent report showed that, among the 22 ICU patients who were intubated, 19 $(86 \%)$ of them died. ${ }^{3}$ Shoemaker et al.'s work highlights the importance of timely reduction of oxygen debt using effective oxygenation and ventilation therapies.

Cross infection among healthcare workers were there in the early outbreak when self-protection was not much established. Transmission mechanics are still unknown. Withholding intubation may outweigh the risk of cross infection. HCW should wear personal protection equipment (PPE) strictly. Efficient education should be provided for donning such as hair cover, fit-tested N95 respirator, water proof gown, double gloving, eye and face shield, and water proof shoe covers. ${ }^{4}$ An experienced assistant should be there to check for donning and doffing process and provide feedback. Details for doffing process were explained including hand hygiene, eye and face shield removal, gown removal, outer glove removal, shoe cover removal, inner glove removal, hand hygiene, N95 respirator or equivalent removal, and hair cover removal. ${ }^{4} \mathrm{~A}$ shower and the use of oral, nasal, and external auditory canal disinfectants are recommended after the removal of personal protective equipment.

When COVID-19 patient requires intubation, they have no respiratory reserve with exhausted compensatory mechanisms. With very low oxygen saturation with loss of breathing as common presentation, a careful airway management plan should be made. - $^{4}$ PPE could make the intubation process difficulty and with psychological stress of cross infection could make an easy intubation difficult. 
Preparation includes oxygen, an assistant (helper), monitor, suction, machine (ventilator), airway materials, intravenous access and medications (drugs) as acronym OH-MS MAID. With one-time use disposable supplies, an efficient airway evaluation should be initiated before intubation. Two single-use filters should be placed in the inhalation and exhalation breathing circuits. Bacterial filters had been used for Influenza in the past and were observed to be capable of preventing the infection. ${ }^{5}$ Well-fitted facemask should be used for pre-oxygenation. Noninvasive ventilation should be used with $100 \% \mathrm{FiO}_{2}$ to maximize oxygenation. These measures yet need to show promise due to gap in improved oxygenation and unpredictable outcomes. Although the aerosol-generating potential of noninvasive ventilation is a potential concern to some providers, ${ }^{6}$ it is being widely used amid this outbreak.

Mechanical ventilation includes low tidal volume ventilation (4-8 $\mathrm{mL} / \mathrm{kg}$ of predicted body weight), targeting plateau pressures of $<30 \mathrm{~cm} \mathrm{H}_{2} \mathrm{O}$, conservative fluid strategy, a higher positive end-expiratory pressure (PEEP) strategy and prone ventilation for 12 to 16 hours per day. ${ }^{4-6}$ Neuromuscular blocking agents are recommended to facilitate protective lung ventilation, persistent ventilator desynchrony, deep sedation, prone ventilation, or persistently high plateau pressures. ${ }^{4-6}$ Further recommendations include head up positioning $\left(30-45^{\circ}\right)$ to improve oxygenation and reduce risk of ventilator associated pneumonia.

Indications for early intubation has been recommended, based on early COVID-19 experience in China. ${ }^{1-4}$ Some patients progress to refractory hypoxaemia rapidly, and an awareness that preparation for intubation takes longer given the need for airborne/contact precautions. However, reports from the COVID-19 pandemic suggest that some patients who have severe hypoxaemia can avoid intubation if they are otherwise stable. ${ }^{4-6}$ Pre-oxygenation should involve a tight-fitting mask. Patients refractory to pre-oxygenation (e.g. unable to achieve $\mathrm{SpO}_{2}>90-95 \%$ ) likely have "shunt" physiology and may require continuous positive pressure ventilation for preoxygenation. Risk of viral transmission is avoided further through the use of viral filter on ventilators, rapid sequence induction with avoidance of bag mask ventilation (unless required for re-oxygenation), avoid cricoid pressure (may stimulate cough / vomiting and worsen view), routine use of video-laryngoscopy and avoiding auscultating the chest post-intubation.

Modified rapid sequence intubation with agents such as Midazolam 1 to $2 \mathrm{mg}$ for anxious patients, lidocaine, $1.5 \mathrm{mg} / \mathrm{Kg}$ for cough suppression, etomidate $(0.2$ to $0.3 \mathrm{mg} / \mathrm{Kg})$ for patients with hemodynamic instability or propofol (1 to $1.5 \mathrm{mg} / \mathrm{Kg}$ ) for stable patients. Fentanyl (50 to $100 \mathrm{mcg}$ ) may be used to suppress laryngeal reflexes and optimize the intubation condition. ${ }^{5-6}$ Gentle airway manipulation is warranted. It is prudent to use video laryngoscopy rather than direct laryngoscopy for intu- bation to minimize the risk of cross infection. Same precautions should be considered during extubation.

Due to lack of guidelines, we are adopting ARDS guidelines already established for severe hypoxic patients. ${ }^{1-5}$ The widely used practice after lung recruitment maneuvers, is to set PEEP at $20 \mathrm{~cm} \mathrm{H}_{2} \mathrm{O}$ and titrate down in a decrement of 2 to $3 \mathrm{~cm} \mathrm{H}_{2} \mathrm{O}$. No mode of ventilation has been suggested to be superior to others. ${ }^{3}$ Awake prone ventilation or mechanical ventilation in the prone position improves oxygenation and lung recruitment. ${ }^{5}$ Further precaution could be taken for reduction of aerosol generation post-intubation with endotracheal tube cuff pressure checks, in-line suction and tight circuit connections. ${ }^{4-6}$

It is appropriate to be conservative with intravenous fluids in patients with severe lung injury if there are no signs of tissue hypoperfusion. ${ }^{2}$ Early dexamethasone administration may reduce overall mortality and mechanical ventilation duration in ARDS patients. ${ }^{5}$ Extracorporeal membrane oxygenation showed promise in selected patients and a review suggested mortality reduction in patients with ARDS hence can be used as a salvage options in severe hypoxemia. ${ }^{2-6}$ With acute refractory hypoxemia, timely intubation is superior to decrease oxygen debt.

\section{CONFLICT OF INTEREST:}

Authors declared no conflict of interest.

\section{AUTHORS' CONTRIBUTION:}

SS, MAB: Drafted the manuscript significantly in terms of conceiving, editing and reviewing.

\section{REFERENCES}

1. Guan WJ, Ni ZY, Hu Y, Liang WH, Ou CQ, He JX, et al. Clinical characteristics of coronavirus disease 2019 in China. N EnglJ Med 2020; 382(18):1708-20.

2. Ramanathan K, Antognini D, Combes A, Paden M, Zakhary $B$, Ogino $M$, et al. Planning and provision of ECMO services for severe ARDS during the COVID-19 pandemic and other outbreaks of emerging infectious diseases. Lancet Respir Med 2020; 8(5):518-26.

3. Chavez S, Long B, Koyfman A, Liang SY. Coronavirus Disease (COVID-19): A primer for emergency physicians. Am J Emerg Med 2020; S0735-6757(20)30178-9.

4. Tolksdorf K, Buda S, Schuler E, Wieler LH, Haas W. Influenza-associated pneumonia as reference to assess seriousness of coronavirus disease (COVID-19). Euro Surveill 2020; 25(11):2000258.

5. Yi Y, Lagniton PNP, Ye S, Li E, Xu RH. COVID-19: What has been learned and to be learned about the novel coronavirus disease. Int J Biol Sci 2020; 16(10):1753-66.

6. Thomas-Rüddel D, Winning J, Dickmann P, Ouart D, Kortgen A, Janssens U, et al. Coronavirus disease 2019 (COVID-19): update for anesthesiologists and intensivists March 2020. Anaesthesist 2020; 69(4):225-35. 